\title{
Absolute position versus relative position in embryo transfer: a randomized controlled trial
}

\author{
Hwang Kwon ${ }^{1,3^{*}}$, Dong-Hee Choi ${ }^{1}$ and Eun-Kyung Kim²
}

\begin{abstract}
Background: Meta-analysis revealed that embryo placement $20 \mathrm{~mm}$ from the fundal endometrial surface resulted in higher pregnancy rate, ongoing pregnancy rate, and live birth rate compared with placement $10 \mathrm{~mm}$ from the fundal endometrial surface. Pregnancy and implantation rates according to relative position were higher when the catheter tip was positioned close to the middle of the endometrial cavity. The aim of the current study is to evaluate differences in implantation and pregnancy rates if the site of embryo transfer is $2 \mathrm{~cm}$ distance from the fundal endometrium (DFE) compared to the midpoint of the endometrial cavity length (ECL).

Methods: Patients were randomized to one of two groups: in group A ( $n=98,98$ IVF-ET cycles), the embryo transfer catheter tip was positioned $2 \mathrm{~cm}$ DFE, while that in group B ( $n=97,97$ IVF-ET cycles) was positioned at the midpoint of the ECL. We compared pregnancy outcomes of implantation rate, chemical pregnancy rate, clinical pregnancy rate, ongoing pregnancy rate, ectopic pregnancy rate, and miscarriage rate in the two groups.

Results: Analysis of implantation rate (19.5 \pm 27.7 vs. $21.7 \pm 32.6 ; p=0.6)$, chemical pregnancy rate (51\% vs. $50.5 \% ; p=0.94)$, clinical pregnancy rate (35.7\% vs. $38.1 \% ; p=0.73)$, ongoing pregnancy rate $(31.6 \%$ vs. $30.9 \%$; $p=0.92)$, ectopic pregnancy rate ( $8.6 \%$ vs. $2.7 \% ; p=0.35)$, and miscarriage rate $(11.4 \%$ vs. $16.2 \% ; 0.74)$ revealed comparable results for both groups.
\end{abstract}

Conclusions: Implantation and pregnancy rates were not influenced by the site of the ET catheter tip being $2 \mathrm{~cm}$ DFE compared to at the midpoint of the ECL.

Trial Registration: ISRCTN: ISRCTN15972342

Keywords: Site of embryo transfer, Absolute position, Relative position, fundal endometrium, Endometrial cavity length

\section{Background}

Embryo transfer is one of the most important factors affecting the rate of successful pregnancy in IVF-ET. Variables in ET such as removal of cervical mucus [1, 2], sonoguidance [3-6], catheter type [7-13], catheter loading technique [14-16], presence of blood on the catheter tip [17], bacterial contamination $[18,19]$, and site of embryo deposition [20-22] are all determinants of a successful pregnancy.

\footnotetext{
* Correspondence: khlsm98@dreamwiz.com

'Department of Obstetrics and Gynecology, CHA Fertility Center of Bundang CHA General Hospital, CHA University, Seongnam, Korea

${ }^{3}$ College of Medicine, CHA University and CHA Fertility Center of Bundang

CHA General Hospital, 351 Yatap-dong, Bundang-gu, Seongnam,

Gyeonggi-do 463-712, Korea
}

Full list of author information is available at the end of the article
There has been debate regarding which area within the endometrial cavity is ideal for embryo placement in order to obtain the highest pregnancy rate. Various studies regarding the relationship between embryo transfer site and pregnancy outcome have been divided analysis into two categories: absolute position according to distance from the fundal endometrium (DFE) and relative position according to endometrial cavity length (ECL). It is not easy to determine whether the embryo deposition site should be chosen based on absolute position from the fundal endometrium or by relative position according to endometrial cavity length. In a previous randomized controlled trial (RCT) on absolute position, pregnancy rate was significantly higher when the embryo was deposited $20 \mathrm{~mm}$ caudal to the fundus compared to when it was deposited $10 \mathrm{~mm}$ caudal to the fundus (60\% vs. $39.3 \%$ ) 
[20]. A meta-analysis found that embryo placement $20 \mathrm{~mm}$ from the fundal endometrial surface resulted in higher pregnancy rate, ongoing pregnancy rate, and live birth rate compared with placement $10 \mathrm{~mm}$ from the fundal endometrial surface [23]. One research group reported that pregnancy and implantation rates did not vary according to the distance between the catheter tip and fundal endometrium (group 1: $10-15 \mathrm{~mm}$, group 2: $16-20 \mathrm{~mm}$, and group $3: \geq 21 \mathrm{~mm}$ ), but that pregnancy and implantation rates according to the relative position of the catheter tip in endometrial cavity were higher when the catheter tip was positioned close to the middle of the endometrial cavity (group 1: upper $40 \% \mathrm{ECL}$, group 2: upper $40 \%$ to midpoint ECL, group 3: from the midpoint to lower $40 \% \mathrm{ECL}$, and group 4 : lower $40 \% \mathrm{ECL}$ ) [22].

Although discrepancies exist regarding pregnancy rates according to the absolute or relative position of the catheter tip, a 2-cm DFE was considered the reference point for absolute position because that point was associated with a higher pregnancy rate in a meta-analysis [23]. As observed pregnancy and implantation rates were higher in the midpoint ECL in a RCT evaluating relative position, midpoint ECL was considered the reference point for relative position. The aim of this current prospective $\mathrm{RCT}$ is to compare the differences in implantation and pregnancy rates at an absolute position $2 \mathrm{~cm}$ from the fundal endometrium and a relative position at the midpoint of the endometrial cavity.

\section{Methods}

This randomized controlled trial was approved by the Institutional Review Board at our hospital. A total of 197 patients were enrolled in the IVF-ET (ICSI) program at the CHA Fertility Center (CHA University, Seongnam, Korea) between July 2012 and December 2014. All patients provided written informed consent. The study was registered under ISRCTN registry number (ISRCTN 15972342).

\section{Sample size and randomization}

The null hypothesis is that the rates for groups $\mathrm{A}$ and $\mathrm{B}$ are equal. The sample size was calculated to prevent type II errors. In previous articles, pregnancy rates at $2 \mathrm{~cm}$ distance from fundal endometrium [20] and the central area of the endometrial cavity [22] were $60 \%$ and $36.7 \%$, respectively. Based on these differences, 84 cases in each group would be needed with a two-sided alpha level of 0.05 and a beta level of 0.20 ( $80 \%$ power). This sample size calculation was done so that the null hypothesis was not accepted with a probability of $80 \%$. Thus, the target number of subjects for each group was 100 (a total of 200) to allow dropouts. Randomization was performed using a computer-generated random number list in blocks of four. An allocation list was sealed in an envelope and the physician transferring embryos opened the envelope just before ET.

\section{Study design}

197 patients were randomized to one of two groups: group A or group B. In group A $(n=100)$, the embryo transfer catheter tip was positioned $2 \mathrm{~cm}$ from the fundal endometrium. In group $B(n=97)$, the embryo transfer catheter tip was positioned at the midpoint of the endometrial cavity length, between the internal os of the uterine cervix and the fundal endometrium. The current study included only fresh embryo transfer cycles. Two patients were excluded from group A, including one patient in which all embryos were frozen for prevention of OHSS and the other patient in which embryos were not transferred by the same physician due to the absence of a physician (Fig. 1).

\section{Stimulation protocol and oocyte retrieval}

All patients were pretreated with GnRH agonist (Lorelin'; Dongkook, Korea) $0.5 \mathrm{mg} /$ day from 10 days prior to the start of menstruation until day 2 of the next menstrual cycle for suppression of the pituitary gland. The patients' ovaries were stimulated with a combination of recombinant follicle-stimulating hormone (FSH, subcutaneous) and human menopausal gonadotropin (hMG, intramuscular) from day 3 of the menstrual cycle until one day before hCG administration. hCG (Ovidrel'; Merck-Serono, Italy) was administered when at least two follicles with an average diameter $\geq 18 \mathrm{~mm}$ were observed on ultrasonography. Oocytes were retrieved 35 hours after hCG injection and were subsequently fertilized by IVF or ICSI. On day 2 or 3 , all embryos were evaluated for cell number and morphology. Each embryo transferred was evaluated for blastomere size and fragmentation. Embryos were graded as follows. Those with equal blastomere size and no fragmentation were considered Grade 1; those with blastomeres of equal size with slight fragmentation $(<20 \%)$ were Grade 2; those with blastomeres of unequal size but no fragmentation were Grade 3; those with blastomeres of equal or unequal size and moderate fragmentation (20\%-50\%) were Grade 4; and those with unrecognizable blastomeres and severe fragmentation ( $>50 \%$ ) were Grade 5 [24]. The embryos were transferred on postretrieval day 2 or 3 .

\section{Embryo transfer}

After bladder filling, patients were placed in the lithotomy position, and the cervix was visualized using a speculum. The vagina and exocervix were cleaned with sterile gauze, and endocervical mucus was removed with a cotton swab. We measured the distance between the internal os of the cervix and the fundal endometrium using $5 \mathrm{MHz}$ transabdominal ultrasonography (Aloka SSD-4000; Hitachi Aloka Medical Ltd., Japan) in both 


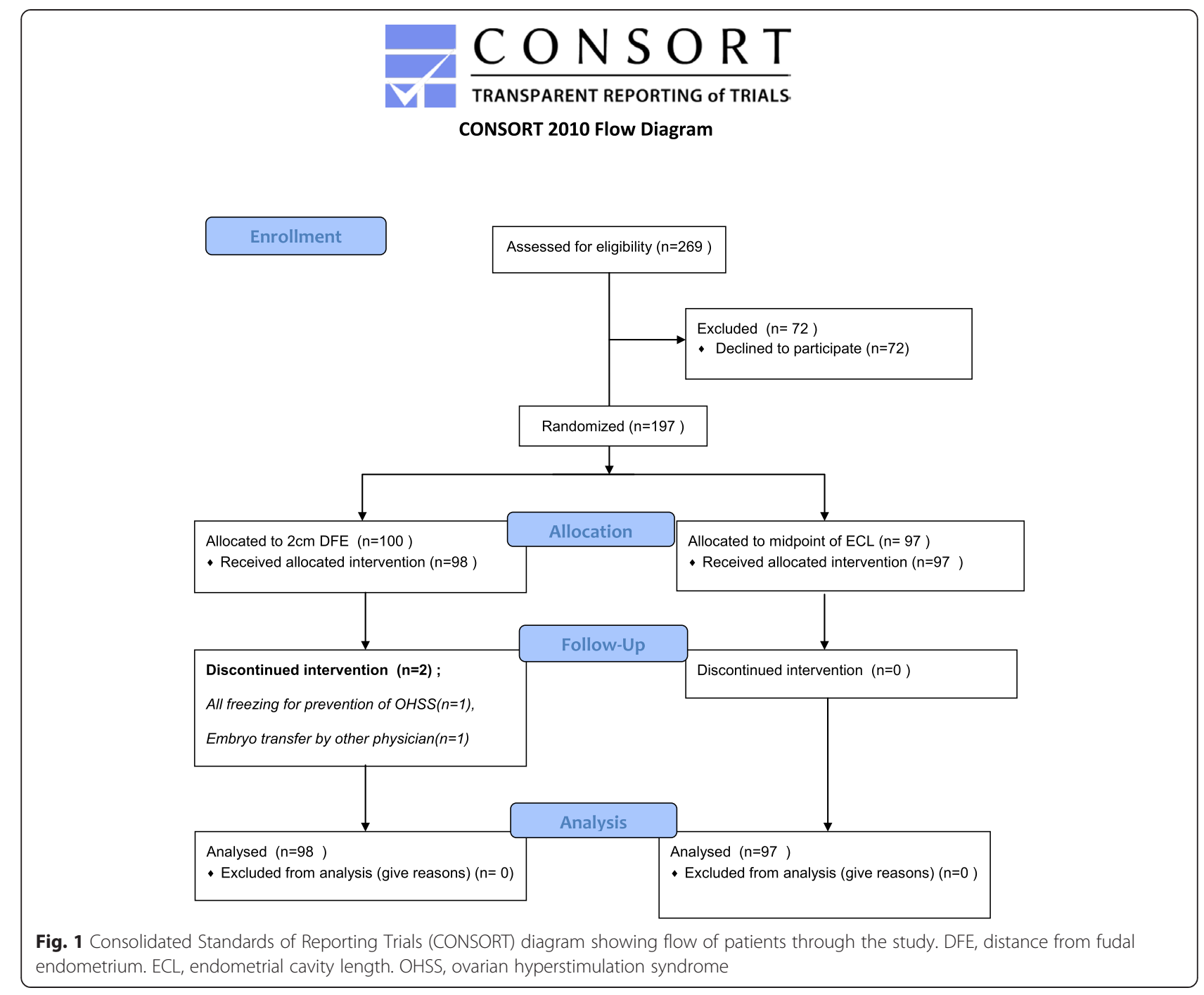

groups of patients. This distance was measured only once and was considered the endometrial cavity length (ECL). The ECL and the midpoint of the ECL were recorded. A Sydney-Cook catheter external guide was inserted into the endometrial cavity through the endocervical canal. We measured the distance from the tip of the external guide to the fundal endometrium only once and estimated the position of the internal catheter tip loaded with the embryos. After the internal catheter tip passed through the external guide and was positioned $2 \mathrm{~cm}$ from the fundal endometrium (DFE) in group A and at the midpoint of the ECL in group $\mathrm{B}$, the embryos were expelled. The catheter was immediately removed and examined under a stereomicroscope to determine whether the embryos remained in the catheter tip. It was recommended that patients remain supine in bed for 2 hours after emptying their bladder [25]. All embryo transfers were performed by the same physician.
Micronized progesterone (Utrogestan ${ }^{\oplus} 200$ mg Vaginal Capsule; Capsugel, France) was inserted into the vagina three times per day beginning on the day of oocyte retrieval for luteal support. Pregnancy was determined by serum $\beta$ hCG level 13 days after embryo transfer.

\section{Outcome measures}

To determine the difference in general characteristics of patients, the following factors were compared in groups $\mathrm{A}$ and $\mathrm{B}$ : age, etiology of infertility, body mass index (BMI), AMH, antral follicle count (AFC), and duration of infertility. Also, for comparison of ovarian stimulation, oocyte retrieval, and IVF outcome in groups A and B, the following factors were recorded: $E_{2}$ and endometrial thickness on the day of hCG administration, number of oocytes retrieved, number of oocytes in metaphase II, fertilization rate, fertilization method, number of embryos transferred, good quality embryos (\%, Grade 1 or 2 embryos 
according to the embryo grading system described above) [24], and endometrial cavity length. We analyzed pregnancy outcomes including implantation rate, chemical pregnancy rate, clinical pregnancy rate, ongoing pregnancy rate, ectopic pregnancy rate, and miscarriage rate. The implantation rate was defined as the number of gestational sacs divided by the number of embryos transferred. Clinical pregnancy was defined as the presence of a gestational sac with fetal heart activity. Ongoing pregnancy was defined as the presence of at least one fetal heart pulsation on ultrasound beyond 12 weeks.

\section{Statistics}

SPSS version 22 was used for statistical analysis. Data are expressed as mean \pm SD or percentage, as appropriate. Student's $t$-test, $\chi^{2}$ test, and Fisher's exact test were used to determine statistical significance. A $p$-value $<0.05$ was considered statistically significant.

\section{Results}

The groups were not significantly different with respect to age, etiology of infertility, BMI, AMH, or AFC. However, there was a significant difference in duration of infertility $(\mathrm{p}=0.025): 3.9 \pm 2.1$ years in group A compared with $4.8 \pm 3.1$ years in group B (Table 1 ). There were no significant differences between groups $\mathrm{A}$ and $\mathrm{B}$ with regard to $\mathrm{E}_{2}$ and endometrial thickness on the day of hCG administration, number of oocytes retrieved, number of oocytes in metaphase II, fertilization rate, fertilization method, number of embryos transferred, or percentage of good quality embryos. The two groups were also not significantly different with regard to endometrial cavity length $(4.8 \pm 0.7$ vs. $4.8 \pm 0.8 ; \mathrm{p}=0.94)$ or the difference between midpoint and 2 -cm DFE $(0.4 \pm 0.3$ vs. $0.4 \pm 0.4$; $\mathrm{p}=0.98$ ) (Table 2). Mean DFE was $2 \mathrm{~cm}$ in group A and $2.38 \pm 0.4$ in group B. Analysis of implantation rate (19.5 \pm 27.7 vs. $21.7 \pm 32.6 ; \mathrm{p}=0.6)$, chemical pregnancy rate (51 \% vs. $50.5 \%$; $\mathrm{p}=0.94)$, clinical pregnancy rate (35.7 \% vs. $38.1 \% ; \mathrm{p}=0.73$ ), ongoing pregnancy rate (31.6\% vs. $30.9 \% ; \mathrm{p}=0.92)$, ectopic pregnancy rate ( $8.6 \%$ vs. $2.7 \%$; $=0.35)$, and miscarriage rate $(11.4 \%$ vs. $16.2 \%$; 0.74) revealed comparable results for both groups (Table 3 ).

\section{Discussion}

This randomized controlled study demonstrated that implantation and pregnancy rates of patients in whom the embryo transfer catheter tip was positioned $2 \mathrm{~cm}$ from the fundal endometrium were comparable to those of patients in whom the embryo transfer catheter tip was positioned at the midpoint of the endometrial cavity.

One study group observed position of $3 \sim 6 \mathrm{~mm}$ early gestational sac ( $\mathrm{G} \mathrm{sac}$ ) in the endometrial cavity after spontaneous pregnancy using three-dimensional ultrasound. When the uterine cavity was divided into three portions (upper, middle, and lower), most $G$ sacs were found in the upper region (89.1 \%) [26]. In another study, the location of the G sac was determined via three-dimensional ultrasound after embryo transfer in IVF-ET and $84.4 \%$ of the $G$ sacs were found in the fundal area where embryos were initially transferred.

Table 1 General characteristics of all patients studied

\begin{tabular}{|c|c|c|c|}
\hline & Group A:DFE $2 \mathrm{~cm}$ & Group B: midpoint of ECL & $p$ value \\
\hline Patients (n) & 98 & 97 & \\
\hline cycles (n) & 98 & 97 & \\
\hline Age (years) $( \pm S D)$ & $34.1 \pm 3.8$ & $34.1 \pm 3.4$ & 0.87 \\
\hline Etiology & & & 0.55 \\
\hline Tubal factor & 19 & 21 & \\
\hline Male factor & 8 & 12 & \\
\hline POR & 7 & 4 & \\
\hline Нyро-Нуро & 1 & 0 & \\
\hline POR + tubal & 0 & 1 & \\
\hline uterine & 0 & 1 & \\
\hline Unexplained & 63 & 58 & \\
\hline $\mathrm{BMI}(\mathrm{Kg} / \mathrm{m} 2)( \pm \mathrm{SD})$ & $21 \pm 2.4$ & $21.4 \pm 3.2$ & 0.33 \\
\hline $\mathrm{AMH}(\mathrm{ng} / \mathrm{ml})( \pm \mathrm{SD})$ & $3.5 \pm 2.9$ & $3.6 \pm 3.2$ & 0.67 \\
\hline $\mathrm{AFC}( \pm \mathrm{SD})$ & $20.6 \pm 8.6$ & $21.5 \pm 8.0$ & 0.44 \\
\hline Duration of infertility $(y r s),( \pm S D)$ & $3.9 \pm 2.1$ & $4.8 \pm 3.1$ & 0.025 \\
\hline
\end{tabular}

DFE = distance from fundal endometrium, $\mathrm{ECL}$ = endometrial cavity length

$\mathrm{POR}=$ poor ovarian response, Hypo-Hypo $=$ Hypogonadotropic hypogonadism

$\mathrm{AFC}=$ antral follicle count 
Table 2 Ovarian stimulation, oocyte retrieval, and IVF outcome of all patients studied

\begin{tabular}{|c|c|c|c|}
\hline & Group A: DFE $2 \mathrm{~cm}$ & Group B: midpoint of ECL & $\mathrm{p}$ value \\
\hline $\mathrm{E}_{2}$ on hCG day $(\mathrm{pg} / \mathrm{mL})( \pm \mathrm{SD})$ & $2740.9 \pm 1413.3$ & $2787.7 \pm 1544.4$ & 0.83 \\
\hline Endometrial thickness on hCG day $(\mathrm{mm})( \pm \mathrm{SD})$ & $10.4 \pm 2.2$ & $10.1 \pm 2.2$ & 0.3 \\
\hline No. of oocyte retrieval $( \pm S D)$ & $12.5 \pm 6.5$ & $13.4 \pm 6.8$ & 0.32 \\
\hline No. of oocytes in metaphase II ( \pm SD) & $7.3 \pm 4.9$ & $7.9 \pm 5.0$ & 0.41 \\
\hline Fertilization rate $(\%)( \pm S D)$ & $68.6 \pm 18.7$ & $68.3 \pm 17.4$ & 0.92 \\
\hline Fertilization method & & & 0.61 \\
\hline Conventional IVF & 9 & 8 & \\
\hline$|\mathrm{CS}|$ & 51 & 44 & \\
\hline Split IVF-ICSI & 38 & 44 & \\
\hline No. of embyos transferred $( \pm$ SD) & $2.8 \pm 0.8$ & $2.8 \pm 0.7$ & 0.78 \\
\hline Good quality embyos (\%) ( \pm SD) & $70.7 \pm 34.8$ & $76.7 \pm 29.7$ & 0.19 \\
\hline $\mathrm{ECL}(\mathrm{cm})( \pm \mathrm{SD})$ & $4.8 \pm 0.7$ & $4.8 \pm 0.8$ & 0.94 \\
\hline Difference between midpoint and DFE2cm ( \pm SD) & $0.4 \pm 0.3$ & $0.4 \pm 0.4$ & 0.98 \\
\hline
\end{tabular}

$\mathrm{DFE}=$ distance from fundal endometrium, $\mathrm{ECL}=$ endometrial cavity length

These results emphasize the importance of embryo transfer [27].

Endometrial blood flow is especially rich around the uterotubal junction outside of the fundal areas. When the G sac is observed daily, it develops near the uterotubal junction and fundus, gradually moving towards the central portion of uterine body [28]. Embryos are apt to implant at a site where endometrial blood flow is rich. Although little research has been done on factors related pregnancy and implantation rates according to deposition of embryos during transfer, the difference in blood flow in the endometrial cavity may play a role.

Many initial reports stated that a site near the fundus is optimal for embryo transfer [29, 30]. However, subsequent studies reported that fundal irritation due to high replacement cause fundal contraction and adversely affect pregnancy rates [31-33].

One retrospective study suggested that, for every additional millimeter the embryos are deposited away from the fundus, the odds of clinical pregnancy increase by $11 \%$ [34]. Another retrospective study reported a higher pregnancy rate with embryo deposition $>10 \mathrm{~mm}$ to $<20 \mathrm{~mm}$ from the fundus [35]. In a previous RCT, higher pregnancy and implantation rates were achieved when the tip was placed between 5 and $15 \mathrm{~mm}$ DFE compared with $>15 \mathrm{~mm}$ DFE [36]. Another RCT reported that an embryo transfer catheter tip positioned between 10 and $15 \mathrm{~mm}$ from the fundus achieved higher clinical pregnancy rate than an embryo catheter tip positioned $\leq 10 \mathrm{~mm}$ from the fundus [37]. When patients were classified into three groups including DFE of $10 \mathrm{~mm}$, $15 \mathrm{~mm}$, and $20 \mathrm{~mm}$ in an earlier RCT, DFE of $20 \mathrm{~mm}$ showed a significantly higher clinical pregnancy rate than DFE of $10 \mathrm{~mm}$ (60\% vs. $39.3 \%$ ) [20].

Consistent results were not observed in the above RCT studies with respect to absolute position from the fundal endometrium. However, a meta-analysis of three articles [20, 21, 38] using the Mantel - Haenszel method and utilizing the fixed-effects model revealed that clinical pregnancy rate, ongoing pregnancy rate, and live birth rate were significantly higher for a $20 \mathrm{~mm}$ versus $10 \mathrm{~mm}$ distance from the fundal endometrium [23]. Based on this meta-analysis, a 2-cm DFE was considered the optimal site of absolute position in the current study.

One prospective cohort study divided patients into two groups: a fundal group (embryos were deposited

Table 3 Implantation rates, pregnancy rates, and outcome at gestation of all patients studied

\begin{tabular}{llll}
\hline & Group A: DFE2cm & Group B: midpoint of ECL & $p$ value \\
\hline Implantation rates (\%) & $19.5 \pm 27.7$ & $21.7 \pm 32.6$ & 0.6 \\
Chemical pregnancy rates & $51.0 \%(50 / 98)$ & $50.5 \%(49 / 97)$ & 0.94 \\
Clinical pregnancy rate & $35.7 \%(35 / 98)$ & $38.1 \%(37 / 97)$ & 0.73 \\
Ongoing pregnancy rates & $31.6 \%(31 / 98)$ & $30.9 \%(30 / 97)$ & 0.92 \\
Ectopic pregnancy & $8.6 \%(3 / 35)$ & $2.7 \%(1 / 37)$ & 0.35 \\
Miscarriage rate & $11.4 \%(4 / 35)$ & $16.2 \%(6 / 37)$ & 0.74 \\
Mole & $0 \%$ & $2.8 \%(1 / 37)$ & 1 \\
\hline
\end{tabular}

$\mathrm{DFE}=$ distance from fundal endometrium, $\mathrm{ECL}=$ endometrial cavity length 
within $0.5-1.0 \mathrm{~cm}$ of the uterine fundus) and a lower-tomiddle group (embryos were deposited at the central portion of the ECL to the lower third of the ECL). Comparison of these two groups revealed that clinical pregnancy rate, implantation rate, and birth rate were significantly higher in the lower-to-middle segment ET group compared with the fundal ET group [39]. Another RCT showed that placing embryos in the upper half of the uterine cavity did not improve pregnancy rate compared with that of embryos placed in the lower half [21]. These research group randomized patients into three groups according to the distance between the fundal endometrial surface and the catheter tip (group 1: 10-15 mm, group 2: 16-20 mm, group 3: $\geq 21 \mathrm{~mm}$ ) and compared the pregnancy and implantation rates between groups. They also randomly assigned patients to four groups according to the relative position in the endometrial cavity (group 1: $<40 \%$, group 2: 41-50 \%, group 3: 51-60 \%, group 4: $\geq 61 \%$ ) and compared the pregnancy and implantation rates between groups. Pregnancy and implantation rates according to absolute position were not significantly different, but pregnancy and implantation rates according to relative position were higher when the catheter tip was positioned close to the middle of the endometrial cavity [22]. When we analyzed these three studies with respect to relative position of embryo transfer, the optimal site for relative positioning of the embryo transfer was the midpoint of the ECL.

The current study was designed to compare absolute position $(2 \mathrm{~cm}$ DFE) with relative position (midpoint of the ECL) of embryo transfer. In comparing general characteristics of all patients studied, the duration of infertility in group $B$ (midpoint of the ECL) was significantly higher than that of group A (2 cm DFE). However, this difference in duration of infertility did not seem to correlate with dissimilarity in general characteristics, since there were no differences between groups in age, BMI, etiology of infertility, or ovarian reserve indicators $(\mathrm{AMH}$, AFC). There were also no differences in implantation, clinical pregnancy, or ongoing pregnancy rates between the two groups. The mean difference between the midpoint (group A) and 2-cm DFE (group B) was only $4 \mathrm{~mm}$. In most other reports, embryo transfer depth was classified in $5-\mathrm{mm}$ increments from the fundal endometrium $[22,35,37]$. Thus, a difference of less than $5 \mathrm{~mm}$ is not considered to affect pregnancy outcomes. Overall, the minimal difference in DFE between groups A and B resulted in no differences in implantation, clinical pregnancy, or ongoing pregnancy rate.

Therefore, patients with a greater than $0.5 \mathrm{~cm}$ difference between the midpoint of the ECL and $2 \mathrm{~cm}$ DFE (in other words, an ECL $\geq 5 \mathrm{~cm}$ or $\leq 3 \mathrm{~cm}$ ) were classified separately. However, there were no patients with an ECL $\leq 3 \mathrm{~cm}$. A total of 37 women in group A and 34 women in group B had an ECL $\geq 5 \mathrm{~cm}$. The mean ECL of patients with an ECL $\geq 5 \mathrm{~cm}$ was $5.5 \pm 0.5 \mathrm{~cm}$ in group $A$ and $5.6 \pm 0.6 \mathrm{~cm}$ in group $B(p=0.41)$. The ongoing pregnancy rate for group A (DFE $2 \mathrm{~cm}$ ) was significantly higher than that of group $B$ (midpoint of ECL) $(43.2 \%$ vs. $20.6 \%$; $=0.002)$ in women with an $\mathrm{ECL} \geq 5 \mathrm{~cm}$. In cases in which the ECL was longer than $5 \mathrm{~cm}$, our data suggest that positioning the embryo transfer catheter tip more than $2.5 \mathrm{~cm}$ from the fundal endometrium compared with $2 \mathrm{~cm}$ from the fundal endometrium worsens pregnancy outcome.

Although embryo deposition at a relative $50 \%$ ECL may be the best approach in most patients, optimal pregnancy rates in patients with an ECL $\geq 5 \mathrm{~cm}$ are obtained when embryos are placed at a $2-\mathrm{cm}$ DFE.

\section{Conclusions}

In conclusion, implantation and pregnancy rates were not influenced by the site of the ET catheter tip being $2 \mathrm{~cm}$ DFE compared to at the midpoint of the ECL. Since the midpoint ECL in most patients of the relative position group is near the 2-cm DFE, there was no difference in pregnancy outcomes between groups. However, if the ECL is longer than $5 \mathrm{~cm}$, positioning at the midpoint of the ECL was not advantageous. Although the number of patients with an ECL $\geq 5 \mathrm{~cm}$ was small, placing the embryo catheter tip more than $2.5 \mathrm{~cm}$ from the fundal endometrium decreased pregnancy rates in patients with an ECL $\geq 5 \mathrm{~cm}$. Further large-scale studies are needed in patients with an ECL $\geq 5 \mathrm{~cm}$.

\section{Completing interest}

The authors declare that they have no competing interests.

\section{Authors' contribution}

HK designed the study and wrote the manuscript. EK analyzed the data and performed statistics analysis. DC conceived of the study and helped to draft the manuscript. All authors read and approved the final manuscript.

\section{Acknowledgements}

We thank Ji-Sook Ha for helping obtain IRB approval and help in performing the study. This manuscript was edited by editors at eworldediting.

\section{Author details}

${ }^{1}$ Department of Obstetrics and Gynecology, CHA Fertility Center of Bundang CHA General Hospital, CHA University, Seongnam, Korea. ${ }^{2} \mathrm{CHA}$ Fertility Center of Bundang CHA General Hospital, CHA University, Seongnam, Korea. ${ }^{3}$ College of Medicine, CHA University and CHA Fertility Center of Bundang CHA General Hospital, 351 Yatap-dong, Bundang-gu, Seongnam, Gyeonggi-do 463-712, Korea.

Received: 8 April 2015 Accepted: 3 July 2015

Published online: 29 July 2015

\section{References}

1. Eskandar MA, Abou-Setta AM, El-Amin M, Almushait MA, Sobande AA. Removal of cervical mucus prior to embryo transfer improves pregnancy rates in women undergoing assisted reproduction. Reprod Biomed Online. 2007;14:308-13.

2. Visschers BA, Bots RS, Peeters MF, Mol BW, van Dessel HJ. Removal of cervical mucus: effect on pregnancy rates in IVF/ICSI. Reprod Biomed Online. 2007;15:310-5. 
3. Strickler RC, Christianson C, Crane JP, Curato A, Knight AB, Yang V. Ultrasound guidance for human embryo transfer. Fertil Steril. 1985:43:54-61.

4. García-Velasco JA, Isaza V, Martinez-Salazar J, Landazábal A, Requena A Remohí J, et al. Transabdominal ultrasound-guided embryo transfer does not increase pregnancy rates in oocyte recipients. Fertil Steril. 2002;78:534-9.

5. Buckett WM. A meta-analysis of ultrasound-guided versus clinical touch embryo transfer. Fertil Steril. 2003;80:1037-41.

6. Abou-Setta AM, Mansour RT, Al-Inany HG, Aboulghar MM, Aboulghar MA Serour Gl. Among women undergoing embryo transfer, is the probability of pregnancy and live birth improved with ultrasound guidance over clinical touch alone? A systemic review and meta-analysis of prospective randomized trials. Fertil Steril. 2007;88:333-41.

7. Abou-Setta AM, Al-Inany HG, Mansour RT, Serour Gl, Aboulghar MA. Soft versus firm embryo transfer catheters for assisted reproduction: a systematic review and meta-analysis. Hum Reprod. 2005;20:3114-21.

8. Buckett WM. A review and meta-analysis of prospective trials comparing different catheters used for embryo transfer. Fertil Steril. 2006:85:728-34

9. al-Shawaf T, Dave R, Harper J, Linehan D, Riley P, Craft I. Transfer of embryos into the uterus: how much do technical factors affect pregnancy rates? Assist Reprod Genet. 1993;10:31-6.

10. Ghazzawi IM, Al-Hasani S, Karaki R, Souso S. Transfer technique and catheter choice influence the incidence of transcervical embryo expulsion and the outcome of IVF. Hum Reprod. 1999:14:677-82

11. Urman B, Aksoy S, Alatas C, Mercan R, Nuhoglu A, Isiklar A, et al. Comparing two embryo transfer catheters. Use of a trial transfer to determine the catheter applied. J Reprod Med. 2000;45:135-8.

12. Burke LM, Davenport AT, Russell GB, Deaton JL. Predictors of success after embryo transfer: experience from a single provider. Am J Obstet Gynecol. 2000;182:1001-4

13. Saldeen P, Abou-Setta AM, Bergh T, Sundström P, Holte J. A prospective randomized controlled trial comparing two embryo transfer catheters in an ART program. Fertil Steril. 2008;90:599-603.

14. Matorras R, Mendoza R, Expósito A, Rodriguez-Escudero FJ. Influence of the time interval between embryo catheter loading and discharging on the success of IVF. Hum Reprod. 2004;19:2027-30.

15. Lesny P, Killick SR, Robinson J, Raven G, Maquiness SD. Junctional zone contractions and embryo transfer: is it safe to use a tenaculum? Hum Reprod. 1999:14:2367-70

16. Martínez F, Coroleu B, Parriego M, Carreras O, Belil I, Parera N, et al. Ultrasound-guided embryo transfer: immediate withdrawal of the catheter versus a 30 second wait. Hum Reprod. 2001;16:871-4.

17. Goudas VT, Hammitt DG, Damario MA, Session DR, Singh AP, Dumesic DA Blood on the embryo transfer catheter is associated with decreased rates of embryo implantation and clinical pregnancy with the use of in vitro fertilization-embryo transfer. Fertil Steril. 1998;70:878-82.

18. Egbase PE, al-Sharhan M, al-Othman S, al-Mutawa M, Udo EE, Grudzinskas $J G$. Incidence of microbial growth from the tip of the embryo transfer catheter after embryo transfer in relation to clinical pregnancy rate following in-vitro fertilization and embryo transfer. Hum Reprod. 1996;11:1687-9.

19. Moore DE, Soules MR, Klein NA, Fujimoto WY, Agnew KJ, Eschenbach DA. Bacteria in the transfer catheter tip influence the live-birth rate after in vitro fertilization. Fertil Steril. 2000;74:1118-24.

20. Coroleu B, Barri PN, Carreras O, Martínez F, Parriego M, Hereter L, et al. The influence of the depth of embryo replacement into the uterine cavity on implantation rates after IVF: a controlled, ultrasound-guided study. Hum Reprod. 2002;17:341-6.

21. Franco Jr JG, Martins AM, Baruffi RL, Mauri AL, Petersen CG, Felipe V, et al. Best site for embryo transfer: the upper or lower half of endometrial cavity? Hum Reprod. 2004;19:1785-90.

22. Oliveira JB, Martins AM, Baruffi RL, Mauri AL, Petersen CG, Felipe $V$, et al. Increased implantation and pregnancy rates obtained by placing the tip of the transfer catheter in the central area of the endometrial cavity. Reprod Biomed Online. 2004;9:435-41.

23. Abou-Setta AM. What is the best site for embryo deposition? A systematic review and meta-analysis using direct and adjusted indirect comparisons. Reprod Biomed Online. 2007:14:611-9.

24. Veeck LL. Atlas of the Human Oocyte and Early Conceptus. Baltimore, MD: Williams and Wilkins; 1991.

25. Lewin A, Schenker JG, Avrech O, Shapira S, Safran A, Friedler S. The role of uterine straightening by passive bladder distension before embryo transfer in IVF cycles. J Assist Reprod Genet. 1997;14:32-4
26. Minami S, Ishihara K, Araki T. Determination of blastocyst implantation site in spontaneous pregnancies using three-dimensional transvaginal ultrasound J Nippon Med Sch. 2003;70:250-4.

27. Baba K, Ishihara O, Hayashi N, Saitoh M, Taya J, Kinoshita K. Where does the embryo implant after embryo transfer in humans? Fertil Steril. 2000;73:123-5

28. Kinoshita K. Clinical significance of detection time and site of early gestational sac by ultrasonography. Nihon Sanka Fujinka Gakkai Zasshi. 1994;46:102-8

29. Kerin JF, Jeffrey R, Warnes GM, Cox LW, Broom TJ. A simple technique for human embryo transfer into the uterus. Lancet. 1981;2:726-7.

30. Leeton J, Trounson A, Jessup D, Wood C. The technique for human embryo transfer. Fertil Steril. 1982:38:156-61.

31. Fanchin R, Righini C, Olivennes F, Taylor S, de Ziegler D, Frydman R. Uterine contractions at the time of embryo transfer alter pregnancy rates after in-vitro fertilization. Hum Reprod. 1998;13:1968-74.

32. Lesny P, Killick SR, Tetlow RL, Robinson J, Maguiness SD. Embryo transfer-can we learn anything new from the observation of junctional zone contractions? Hum Reprod. 1998;13:1540-6.

33. Woolcott R, Stanger J. Potentially important variables identified by transvaginal ultrasound-guided embryo transfer. Hum Reprod. 1997:12:963-6

34. Pope CS, Cook EK, Arny M, Novak A, Grow DR. Influence of embryo transfer depth on in vitro fertilization and embryo transfer outcomes. Fertil Steril. 2004;81:51-8.

35. Tiras B, Polat M, Korucuoglu U, Zeyneloglu HB, Yarali H. Impact of embryo replacement depth on in vitro fertilization and embryo transfer outcomes. Fertil Steril. 2010;94:1341-5.

36. Rovei V, Dalmasso P, Gennarelli G, Lantieri T, Basso G, Benedetto C, Revelli A. IVF outcome is optimized when embryos are replaced between 5 and 15 $\mathrm{mm}$ from the fundal endometrial surface: a prospective analysis on $1184 \mathrm{IVF}$ cycles. Reprod Biol Endocrinol. 2013;11. doi: 10.1186/1477-7827-11-114.

37. Pacchiarotti A, Mohamed MA, Micara G, Tranquilli D, Linari A, Espinola SM, et al. The impact of the depth of embryo replacement on IVF outcome. J Assist Reprod Genet. 2007:24:189-93.

38. Nazari A, Askari HA, Check JH, O'Shaughnessy A. Embryo transfer technique as a cause of ectopic pregnancy in in vitro fertilization. Fertil Steril. 1993;60:919-21.

39. Frankfurter D, Trimarchi JB, Silva CP, Keefe DL. Middle to lower uterine segment embryo transfer improves implantation and pregnancy rates compared with fundal embryo transfer. Fertil Steril. 2004;81:1273-7.

\section{Submit your next manuscript to BioMed Central and take full advantage of:}

- Convenient online submission

- Thorough peer review

- No space constraints or color figure charges

- Immediate publication on acceptance

- Inclusion in PubMed, CAS, Scopus and Google Scholar

- Research which is freely available for redistribution

Submit your manuscript at www.biomedcentral.com/submit

C Biomed Central 